Oliveira, S.A. '; Almeida, A. G. '; Bagnato, V.S. ${ }^{2}$; Marcassa, L.G. ${ }^{2}$

\section{9 - Terapia fotodinâmica para tratamento de tumores em cães e gatos}

1 - Clinica Veterinária Amigão, São Carlos-SP

2 - Instituto de Física de São Carlos da Universidade de São Paulo, São Carlos-SP

No início da década de 80 foram realizados os primeiros testes da terapia fotodinâmica para o tratamento de tumores em cobaias. Na década de 90 o uso da terapia fotodinâmica foi autorizado em humanos, e atualmente consiste em uma poderosa técnica disponível $\mathrm{em}$ vários hospitais no mundo. A terapia fotodinâmica (PDT) também tem sido largamente aplicada no tratamento de vários tipos de tumores em cães e gatos com grande sucesso na Europa e Estados Unidos. Esta técnica baseia-se no uso de uma droga fotosensibilizadora, a qual se acumula preferencialmente em células tumorais, e luz laser, a qual transfere energia para o fotosensibilizador. Esta droga reage com o oxigênio molecular no interior da célula transformando-o de tripleto para singleto, o qual é uma forma altamente citotóxica e leva a morte da célula cancerosa. Esta técnica apresenta várias vantagens sobre as técnicas tradicionais, entre elas o baixo custo e a ausência de efeitos colaterais importantes. Sua única restrição é a ausência de luz solar durante 4 semanas após o tratamento. Nosso grupo de pesquisa na USP tem experiência com esta técnica em humanos no Hospital das Clínicas de Ribeirão Preto. Nosso objetivo deste trabalho é estender a aplicação desta a terapia para o tratamento de tumores em cães e gatos e avaliar seus efeitos. Para isto selecionamos dois gatos que apresentavam tumores nasais e um cão com recidiva de tumor mamário. A idade dos animais era superior a 10 anos e já haviam sido tratados por métodos cirúrgicos. Foi administrado o fotosensibilizador, Photogen, em dose de $2 \mathrm{mg} / \mathrm{kg}$ corpóreo. Após vinte quatro horas da aplicação da droga, a região contendo a lesão foi iluminada por luz laser em $630 \mathrm{~nm}$ com potência de $2 \mathrm{~W}$ a uma dose de $300 \mathrm{~J} / \mathrm{cm}^{2}$. Em seguida a iluminação, o animal foi mantido confinado e protegido da luz solar durante quatro semanas, para se evitar queimaduras. Os animais não apresentaram qualquer efeito colateral após a administração da droga e foram medicados apenas com analgésico após a iluminação durante uma semana. Todas as lesões, inclusive com diâmetro superior a 2 $\mathrm{cm}$, foram eliminadas com apenas uma aplicação da terapia fotodinâmica. Um gato e o cão apresentaram recidiva no local tratado 18 meses após o primeiro tratamento. Estes animais passaram por um segundo tratamento semelhante ao primeiro. Neste segundo tratamento substituímos a luz laser por uma fonte de luz alternativa a base de LED, a qual apresenta um custo muito inferior ao laser. Novamente as lesões foram eliminadas à 4 meses atrás e ainda não há sinais de recidiva nem sinais de efeitos colaterais. Concluímos que a terapia fotodinâmica é uma poderosa alternativa para o tratamento de tumores $\mathrm{em}$ animais sem a ocorrência de efeitos colaterais importantes. A princípio pode ser repetida um número ilimitados de vezes, respeitando-se apenas o período de 4 semanas entre uma aplicação e outra; melhorando assim a qualidade de vida do animal. Também concluímos que a fonte de luz alternativa a base de LED é tào eficaz quanto o laser. Devido ao seu custo reduzido em comparação com o laser acreditamos que esta técnica poderá ser popularizada para uso veterinário rapidamente no país. 